\title{
ELABORAÇÃO E VALIDAÇÃO DE UM INSTRUMENTO PARA PREVENÇÃO DE EVENTOS RELACIONADOS A CATETERES VASCULARES
}

\author{
Elke Sandra Alves Rodrigues \\ Enfermeira, Mestranda em Ciências da Saúde pela Faculdade de \\ Enfermagem da Universidade Estadual de Campinas \\ elke alves@yahoo.com.br
}

INTRODUÇÃO: a Organização Mundial da Saúde e a Joint Comission International, destacaram seis áreas prioritárias no que se refere à segurança do paciente e a prevenção do risco de infecções é uma delas. A infecção de corrente sanguínea relacionada ao uso de cateteres está muito presente na assistência à saúde e uma forma de prevenir esse evento é acompanhar a implementação dos protocolos com o intuito de desenvolver capacitações que contribuam para a garantia de melhores resultados. Para que esse processo de vigilância e auditora seja realizado, faz-se necessário o uso de instrumentos validados para este fim. OBJETIVOS: elaborar e validar um instrumento de auditoria dos processos de cobertura, manutenção e manipulação de cateteres vasculares. MÉTODO: estudo metodológico, desenvolvido em quatro etapas: 1) Construção; 2) Validação do conteúdo por um grupo de cinco juízes; 3) Pré-teste e 4) Avaliação da confiabilidade. A coleta dos dados foi realizada em 100 pacientes internados em um hospital terciário e público do interior de São Paulo, com cateter inserido em vasos periféricos ou centrais. Para avaliação da validade foi considerado o Índice de Validade de Conteúdo (IVC) e valores iguais ou superiores a 0,8 foram considerados satisfatórios. Para avaliação da confiabilidade, foi considerada a equivalência interobservadores, onde valores iguais ou superiores a 0,41 foram considerados satisfatórios. O projeto foi aprovado pelo Comitê de Ética em Pesquisa (Protocolo no 2.175.175). RESULTADOS: inicialmente foram elaborados 16 itens. Na primeira rodada de avaliação pelos juízes, nove itens não alcançaram IVC $\geq 0,8$, sendo que sete foram modificados e dois, excluídos. Na segunda rodada, todos os itens alcançaram valores satisfatórios de IVC e a versão para o pré-teste ficou composta por 14 itens. No pré-teste, nenhuma modificação foi sugerida. $\mathrm{Na}$ avaliação da confiabilidade foi obtido um coeficiente Kappa $\geq 0,41$ para todos os itens. CONCLUSÃO: o instrumento "Auditora de Cateteres Vasculares" foi elaborado com sucesso, na medida em que obteve resultados satisfatórios na 
avaliação da validade de conteúdo e confiabilidade interobservador. A utilização do instrumento contribuirá para detecção de fragilidades, capacitação das equipes e revisão dos processos de trabalho com o intuito de garantir a segurança do paciente.

Palavras-chave: Estudos de validação. Infecções relacionadas a cateter. Segurança do paciente. 